\title{
Nitrogen fixation by symbiotic cyanobacteria provides a source of nitrogen for the scleractinian coral Montastraea cavernosa
}

\author{
Michael P. Lesser ${ }^{1, *}$, Luisa I. Falcón ${ }^{2}$, Aimé Rodríguez-Román ${ }^{3}$, Susana Enríquez ${ }^{3}$, \\ Ove Hoegh-Guldberg ${ }^{4}$, Roberto Iglesias-Prieto ${ }^{3}$ \\ ${ }^{1}$ Department of Zoology and Center for Marine Biology, University of New Hampshire, 46 College Road, Durham, \\ New Hampshire 03824, USA \\ ${ }^{2}$ Instituto de Ecología, Universidad Nacional Autónoma de Mexico, CP 04510, México DF, Mexico \\ ${ }^{3}$ Unidad Académica Puerto Morelos, Instituto de Ciencias del Mar y Limnología, Universidad Nacional Autónoma de \\ México, CP 77500, Cancún, Mexico \\ ${ }^{4}$ University of Queensland, Centre for Marine Sciences, Brisbane, Queensland 4072, Australia
}

\begin{abstract}
Colonies of the Caribbean coral Montastraea cavernosa (Linnaeus) that harbor endosymbiotic cyanobacteria can fix nitrogen, whereas conspecifics without these symbionts cannot. The pattern of nitrogen fixation is diurnal and maximum rates occur in the early morning and evening. An analysis of $\delta^{15} \mathrm{~N}$ stable isotope data showed that the zooxanthellae, but not the animal tissue, from colonies with cyanobacteria preferentially use the products derived from nitrogen fixation, and that these zooxanthellae also have a greater DNA content per cell, suggesting that these cells are in the DNA synthesis $(\mathrm{S})$ and gap $\left(\mathrm{G}_{2}\right)+$ mitosis $(\mathrm{M})$ phase of their cell cyle and are preparing to undergo cell division. Since nitrogen fixation did not occur during those times of the day when hyperoxia is known to occur, low oxygen concentrations might be required to support cyanobacterial respiration and provide the energy needed to fix nitrogen because the reaction centers of these cyanobacteria are uncoupled from light harvesting accessory pigments and the photosynthetic electron transport chain. Consistent with this were the depleted $\delta^{13} \mathrm{C}$ stable isotope signatures in all compartments of those corals with symbiotic cyanobacteria, which show an increase in heterotrophy compared with samples of $M$. cavernosa without cyanobacteria. Using modeled underwater light fields and measurements of photosynthesis, we show that the amount of time in which nitrogen fixation in these corals can take place increases with depth and that the distribution of corals with symbiotic cyanobacteria is positively correlated with increasing depth. The results presented here show that the zooxanthellae of $M$. cavernosa acquire nitrogen from cyanobacterial nitrogen fixation. Given that nitrogen limitation has long been proposed to contribute to the stability of these symbiotic associations, the mechanism by which zooxanthellae symbiosis in these corals is maintained remains an important question and the subject of future study.
\end{abstract}

KEY WORDS: Corals $\cdot$ Cyanobacteria $\cdot$ Nitrogen fixation $\cdot$ Stable isotopes $\cdot$ Symbioses

\section{INTRODUCTION}

The role of nitrogen as a limiting nutrient in the ocean over ecological timescales is well-described. One of the most important aspects of nutrient dynamics in the open ocean is the importance of nitrogen fix- ation for the introduction of new nitrogen (Arrigo et al. 2005). While the free-living cyanobacterium Trichodesmium sp. has long been known to be an important nitrogen fixer in tropical oceans, recent studies have shown that the diversity of nitrogen fixers is much greater than previously believed (Arrigo et al. 2005). 
Many of these free-living nitrogen fixers are coccoid cyanobacteria, which lack heterocysts that protect nitrogenase from the deleterious effects of molecular oxygen produced by photosynthesis (Fay 1992, Bergman et al. 1997). In the absence of heterocysts, one alternative strategy to protect nitrogenase from molecular oxygen, or reactive oxygen species (ROS), is to temporally separate photosynthesis and nitrogen fixation (Fay 1992). Oxygen not only inactivates and destroys nitrogenase, but also represses nitrogenase synthesis (Fay 1992). The oxidation of nitrogenase by ROS induces a series of changes in the structure of the protein, rendering the protein incapable of accepting or donating electrons. The sensitivity to oxygen and ROS varies among cyanobacteria, with many species able to fix nitrogen under microaerobic conditions (Fay 1992). Nitrogenase can also be protected by increasing the rate of respiration, which subsequently lowers the concentration of oxygen, or by enhancing antioxidant protection.

Most coral reefs are far removed from anthropogenic effects related to inputs of nutrients, or from areas of natural upwelling where episodic nutrient enrichment occurs. The waters surrounding coral reefs are generally oligotrophic with respect to nitrogen, especially dissolved inorganic nitrogen (DIN); typical measurements of total DIN near reefs are $<1 \mu$ mol $1^{-1}$ (D'Elia \& Wiebe 1990). Corals in mutualistic symbiosis with endosymbiotic dinoflagellates (zooxanthellae) are essential components of the ecological diversity of tropical coral reefs, and their success has been attributed to the evolution of several adaptations to survive in optically clear, low productivity waters in which there is an abundance of solar radiation to drive photosynthesis and low concentrations of ambient DIN. The low concentration of nutrients, specifically nitrogen, is believed to play an essential role in controlling the growth rates of zooxanthellae in hospite and maintaining the stability of the symbiosis (Falkowski et al. 1993).

As in the open ocean, new nitrogen can enter coral reef ecosystems via nitrogen fixation. Most of the nitrogen fixation on coral reefs is facilitated by free-living or benthic prokaryotes, primarily cyanobacteria that then supply both dissolved and particulate organic nitrogen to reefs (Wiebe et al. 1975, D'Elia \& Wiebe 1990). High rates of nitrogen fixation have been measured on coral reefs and are significant with respect to large-scale community requirements (Wiebe et al. 1975). Additionally, several important members of the reef community have the capability to fix nitrogen through mutualistic symbiotic associations, including those of colonial tunicates and sponges.

In addition to their zooxanthellae, a diverse number of bacteria are associated with the tissues of scleractin- ian corals (Rowher et al. 2002, Lesser et al. 2004), and one proposed role for these bacteria has been nitrogen fixation (Rowher et al. 2002, Lesser et al. 2004). Photosynthesis-dependent nitrogen fixation in corals has been reported to be associated with living coral tissue (Williams et al. 1987, Shashar et al. 1994), but most investigators attributed these results to nitrogen-fixing prokaryotes in the surface mucous layer of coral colonies. However, colonies of the Caribbean coral Montastraea cavernosa harbor a population of over $10^{7}$ cells $\mathrm{cm}^{-2}$ of endosymbiotic non-heterocystous coccoid cyanobacteria within the coral tissues, and the available $16 \mathrm{~s}$ rDNA data (556 bp) reveals that these prokaryotes are most similar to either Synechococcus sp. or Prochlorococcus sp. within the order Chroococcales (Lesser et al. 2004). This paraphyletic order (Litvaitis 2002) contains several coccoid and unicellular cyanobacteria that can either fix nitrogen or for which the presence of nitrogenase has been reported (Bergman et al. 1997, Zehr et al. 2001, Steunou et al. 2006). In M. cavernosa, like all corals, the tissues are hyperoxic while net positive photosynthesis is occurring (Shashar et al. 1993, Kühl et al. 1995). The high concentration of oxygen, and the subsequent production of ROS, is potentially deleterious to the nitrogenase protein that is expressed by these symbiotic cyanobacteria (Lesser et al. 2004). Lesser et al. (2004) were unable to resolve several aspects of this novel symbiosis; in particular, whether these cyanobacterial symbionts are actually fixing nitrogen, and what benefits-if any-other components of the holobiont receive. Here we present new data on this microbial consortium, showing that $M$. cavernosa colonies with endosymbiotic cyanobacteria do fix nitrogen, and that the proportion of colonies with endosymbiotic cyanobacteria increases with depth. Nitrogen fixation is confined to those times of the day when physiological hyperoxia or anoxia does not inhibit nitrogen fixation, and the availability of this novel source of inorganic nitrogen does not appear to affect the stability of the mutualistic association between the symbiotic zooxanthellae and the coral host.

\section{MATERIALS AND METHODS}

Sample collection. Samples of Montastraea cavernosa with and without symbiotic cyanobacteria were collected at depths ranging from 3 to $46 \mathrm{~m}$ in waters around Lee Stocking Island, the Bahamas, and Akumal, Mexico. Samples from the Bahamas were used in the depth profile analysis, while all experimental samples were collected from Akumal at midday. The experimental samples were either processed for analysis within $6 \mathrm{~h}$ of collection, or maintained in seawater 
tables with neutral density screening, which simulated the underwater visible irradiance of the collection depth for use in the nitrogen fixation and oxygen flux analyses described below. At each depth, transects were conducted and the first 50 individual colonies of M. cavernosa were scored as being symbiotic with cyanobacteria or not based on the criterion of presence or absence of orange (575 nm) solar stimulated fluorescence as described by Lesser et al. (2004). All samples with cyanobacteria used for experimentation exhibited orange fluorescence over the entire colony, whereas samples in the transects were scored as positive for cyanobacteria even if only part of the colony exhibited orange fluorescence. At any depth where a total of 50 colonies was not scored, the total number of colonies over the same linear distance was used in the analysis (46 m: $\mathrm{n}=20 ; 30 \mathrm{~m}: \mathrm{n}=25 ; 24 \mathrm{~m}: \mathrm{n}=50 ; 15 \mathrm{~m}: \mathrm{n}=50$; $12 \mathrm{~m}: \mathrm{n}=50 ; 9 \mathrm{~m}: \mathrm{n}=50 ; 3 \mathrm{~m}: \mathrm{n}=20$ colonies).

Nitrogen fixation. Nitrogen fixation was measured as the activity of nitrogenase using the acetylene reduction assay (Falcón et al. 2004). Replicate $(\mathrm{n}=3$ ) pieces of coral varying in size from 9 to $14 \mathrm{~cm}^{2}$ were produced from separate larger colonies and their edges allowed to heal for $48 \mathrm{~h}$. Corals with symbiotic cyanobacteria and corals without symbiotic cyanobacteria $(\mathrm{n}=3)$ from $15 \mathrm{~m}$ were then placed in Plexiglas containers containing $185 \mathrm{ml}$ of filtered $(0.22 \mu \mathrm{m})$ seawater and acetylene (20\% of flask volume) with a headspace of $15 \mathrm{ml}$ and constant mixing $(2$ to $3 \mathrm{~cm}$ $\mathrm{s}^{-1}$ ). All samples were placed in an outdoor mesocosm with ambient seawater at a temperature of 25 to $27^{\circ} \mathrm{C}$ and at irradiances similar to the depth of collection. Replicate controls $(n=3)$ of filtered $(0.22 \mu \mathrm{m})$ seawater with acetylene were sampled at the beginning and end of the experiment, while coral samples were sampled at intervals ranging from 1.5 to $4 \mathrm{~h}$ for a total of $24 \mathrm{~h}$ and 11 sampling periods. One ml samples of head gas were taken and placed into $3 \mathrm{ml}$ Vacutainer containers for analysis of ethylene by gas chromatography (Falcón et al. 2004), normalized to coral surface area. Kayanne et al. (2005) compared nitrogen fixation rates using acetylene reduction, ${ }^{15} \mathrm{~N}$ incubations, and the natural abundance of nitrogen isotopes. In their study comparing methods, the rates of acetylene reduction were positively correlated with the nitrogen fixation rates measured directly with ${ }^{15} \mathrm{~N}$ incubations, which supports the validity of using the acetylene reduction rate as a proxy for nitrogen fixation by cyanobacteria. Additionally, natural stable isotopes (see below) reflect the long-term use of the products of nitrogen fixation that accumulate over time, and the balance between nitrogen fixation and denitrification in the system under study (Kayanne et al. 2005). All rates of acetylene reduction were converted to nitrogen fixed using a conversion ratio of $3: 1$
$\left(\mathrm{C}_{2} \mathrm{H}_{2}: \mathrm{N}_{2}\right)$ without considering hydrogenase activity (Kayanne et al. 2005).

Stable isotope analysis. Replicate samples $(n=3)$ of Montastraea cavernosa containing and not containing symbiotic cyanobacteria from $15 \mathrm{~m}$ depth were subjected to removal of both host and symbiont tissue using a Water-pik. These fractions were then separated by centrifugation (5 $\mathrm{min}$ at $4000 \mathrm{rpm}$ ). The host fraction was isolated onto pre-burned glass fiber filters, and the zooxanthellae fraction was acidified to remove skeletal fragments and then isolated on glass fiber filters. Skeletal material was prepared for $\delta^{13} \mathrm{C}$ analysis as described by Rodrigues \& Grottoli (2006). These fractions were combusted in a Carlo Erba NA 1500 elemental analyzer interfaced with a Delta Plus mass spectro-meter for the analysis of $\delta^{15} \mathrm{~N}$ and $\delta^{13} \mathrm{C}$, using air and Vienna Peedee Belemnite Limestone (v-PDB) as standards, respectively.

Oxygen flux and fluorescence analyses. Colonies of brown/green or orange Montastraea cavernosa were collected from $15 \mathrm{~m}$ depth. Samples of brown/green $(n=3)$ and orange $(n=3)$ coral used in the analysis varied in size between 9 and $14 \mathrm{~cm}^{2}$, and were removed from individual parent colonies, cleaned of all epibionts, and their edges allowed to heal for $48 \mathrm{~h}$. These samples were then placed in self-contained Plexiglas respirometers. During measurements, all chambers were constantly stirred ( 2 to $3 \mathrm{~cm} \mathrm{~s}^{-1}$ ) using hydraulically driven magnetic stirrers, while changes in oxygen concentration were measured using calibrated polarographic electrodes (Hansatech Instruments). Data were collected and stored using DATACAN V software (Sable Systems), and then downloaded to a computer as a text file and converted to oxygen concentrations and fluxes. The oxygen flux within each chamber was corrected for the volume displacement of each individual coral and any production in seawater controls. The incident photosynthetically active radiation (PAR; 400 to $700 \mathrm{~nm}$ ) was simultaneously recorded with the oxygen flux data using a quantum sensor (Walz) cross-referenced against a calibrated cosine-corrected light sensor (192SA, LiCor). Photosynthesis and post-illumination respiration were normalized to colony surface area (Marsh 1970) after removal from the respirometer. The oxygen flux data (net photosynthesis) were then plotted and modeled as a photosynthesis-to-irradiance $(P-E)$ curve. Initial plots of the normalized data showed no photoinhibition of photosynthesis at irradiances greater than saturation, as commonly observed in phytoplankton. Consequently, the data were fit using the hyperbolic tangent $P$-E model $P_{i}=P_{S} \times \tanh \left(\alpha I / P_{S}\right)$, where $P_{i}\left(\mu \mathrm{mol} \mathrm{O} \mathrm{Cm}^{-2}\right.$ $\mathrm{h}^{-1}$ ) is the instantaneous rate of photosynthesis normalized to surface area, $P_{S}\left(\mu \mathrm{mol} \mathrm{O}_{2} \mathrm{~cm}^{-2} \mathrm{~h}^{-1}\right)$ is the maximum rate of photosynthesis, $\alpha\left(\mu \mathrm{mol} \mathrm{O} \mathrm{Cm}^{-2} \mathrm{~h}^{-1}[\mu \mathrm{mol}\right.$ 
quanta $\left.\mathrm{m}^{-2} \mathrm{~s}^{-1}\right]^{-1}$ ) is the initial slope of the $P$ - $E$ curve, and $I$ is irradiance $\left(\mathrm{PAR}_{i} \mu \mathrm{mol}\right.$ quanta $\left.\mathrm{m}^{-2} \mathrm{~s}^{-1}\right)$ as described by Jassby \& Platt (1976). The photosynthetic parameters were statistically compared using an unpaired Student's $t$-test, with presence or absence of cyanobacteria (orange vs. brown/green colonies) as the factor at a significance level of $5 \%$.

Excitation/emission curves recorded on orange colonies of Montastraea cavernosa were measured with and without exposure to the herbicide 3-(3,4dichlorophenyl)-1,1-dimethylurea (DCMU) at a concentration of $10 \mu \mathrm{M}$ in EtOH. Maximum excitation was at $550 \mathrm{~nm}$, while maximum emission was between 585 and $590 \mathrm{~nm}$ when measuring phycoerythrin fluorescence. Measurements of the quantum yield of Photosystem II (PSII) fluorescence (the ratio of variable $\left[F_{\mathrm{v}}\right]$ to maximum $\left[F_{\mathrm{m}}\right]$ fluorescence) were taken from darkacclimatized (20 min) corals using a pulse amplitude modulated (PAM) underwater fluorometer (Walz).

Flow cytometry. Samples of corals with and without symbiotic cyanobacteria of approximately 1 to $2 \mathrm{~cm}^{2}$ from $15 \mathrm{~m}$ depth were held upside down and lightly rinsed with copious amounts of filtered $(0.22 \mu \mathrm{m})$ seawater using an air brush to remove excess mucous and associated microbiota. Corals were then vigorously airbrushed to remove coral soft tissues with a small volume (1 to $2 \mathrm{ml}$ ) of filtered seawater. The homogenates were fixed at a final concentration of $0.5 \%$ with electron microscopy grade glutaraldehyde and frozen at $-80^{\circ} \mathrm{C}$. Each sample was screened using $100 \mu \mathrm{m}$ Nitex screen, and the zooxanthellae populations analyzed using a Becton Dickinson FACScan flow cytometer equipped with a $15 \mathrm{~mW}, 488 \mathrm{~nm}$, air-cooled Argon ion laser. The number of zooxanthellae was quantified and the flow cytometer was calibrated with fluorescent beads of various sizes such that when measurements of forward angle light scatter (FALS) were made, they were synonymous with equivalent spherical diameter (ESD). DNA content per zooxanthella was assessed on all samples using the fluorochrome Picogreen (Molecular Probes) (as described by Veldhuis et al. 1997) on up to 4000 events per sample. Excitation of the fluorochrome occurs at $488 \mathrm{~nm}$, and emission signals were collected at $525 \pm 20 \mathrm{~nm}$ only from cells gated between 8 and $25 \mu \mathrm{m}$ as determined by their chlorophyll fluorescent signature. The data are presented as cell counts normalized to the volume measured and expressed as cells $\mathrm{ml}^{-1}$ versus relative fluorescence, smoothed using a Stineman function.

Data analysis. Contingency tables and the Likelihood ratio and Pearson $\chi^{2}$ analyses were used to analyze the proportion of colonies that contained endosymbiotic cyanobacteria at different depths. The nitrogen fixation, stable isotope, flow cytometry, and fluorescence data were statistically analyzed using ANOVA at a significance level of $5 \%$. No unequal variances were detected using the $F_{\max }$ test, and individual treatment differences were assessed using the Student-NeumanKeuls (SNK) multiple comparison test.

\section{RESULTS}

The distribution of Montastraea cavernosa with endosymbiotic cyanobacteria is widespread throughout the Caribbean basin (M. P. Lesser pers. obs.). The proportion of these colonies increased significantly with depth (Likelihood ratio, $\chi^{2}=18.17, \mathrm{p}=0.006$; Pearson, $\chi^{2}=14.065, p=0.03$ ) (Fig. 1 ) in a population of M. cavernosa colonies from the Bahamas. Post-hoc multiple comparison tests showed that the proportion of $M$. cavernosa with symbiotic cyanobacteria was significantly greater at deeper $(\geq 15 \mathrm{~m})$ than at shallow depths $(\leq 12 \mathrm{~m})$, with 32 to $35 \%$ of $M$. cavernosa colonies containing symbiotic cyanobacteria from 15 to $46 \mathrm{~m}$.

Rates of nitrogen fixation in colonies collected from $15 \mathrm{~m}$ show significant effects of colony (ANOVA, $\mathrm{MS}=$ 71.59, $F=107.26, \mathrm{p}<0.001)$, time (ANOVA, $\mathrm{MS}=$ 12.85, $F=19.25, \mathrm{p}<0.001)$ and their interaction (ANOVA, $\mathrm{MS}=12.85, F=19.25, \mathrm{p}<0.001$ ), with greater rates of nitrogen fixation in colonies with cyanobacterial symbionts in both the early morning and late evening on a diel basis (SNK, p < 0.05, Fig. 2) than in con-specifics without symbionts from the same depth, which had no measurable rates of nitrogen fixation. An analysis of the stable isotope data shows that $\delta^{15} \mathrm{~N}$ in the animal tissue fraction of corals with cyanobacteria, while more depleted, was not signifi-

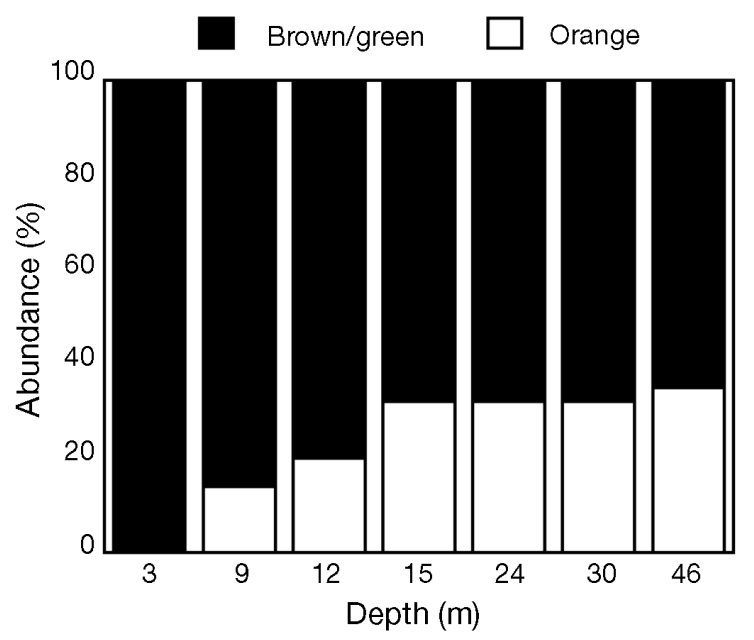

Fig. 1. Montastraea cavernosa. Percent abundance of colonies containing endosymbiotic cyanobacteria at different depths around Lee Stocking Island, the Bahamas 


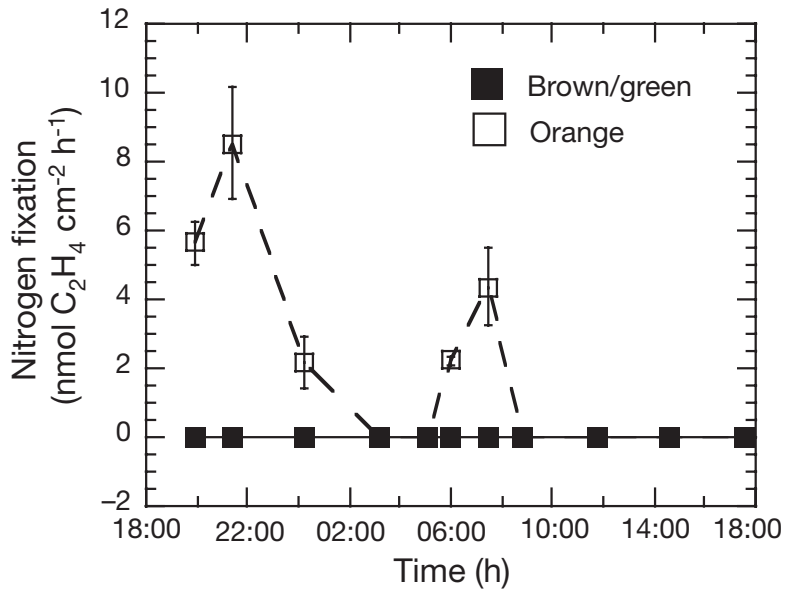

Fig. 2. Montastraea cavernosa. Nitrogen fixation (acetylene reduction) of brown/green $(n=3)$ versus orange $(n=3)$ colonies over $24 \mathrm{~h}$. Results expressed as mean $\pm \mathrm{SE}$

cantly different (ANOVA, MS $=0.467, F=1.58, \mathrm{p}>$ $0.05)$ from that in con-specifics without cyanobacteria (Fig. 2a); in contrast, the zooxanthellae fraction of corals with cyanobacteria showed a significantly (ANOVA, $\mathrm{MS}=12.94, F=9.64, \mathrm{p}=0.036$ ) more depleted $\delta^{15} \mathrm{~N}$ signal (Fig. 3a). Significant differences in the $\delta^{13} \mathrm{C}$ signal of the animal (ANOVA, $\mathrm{MS}=71.59$, $F=107.26, \mathrm{p}<0.001$ ), zooxanthellae (ANOVA, MS = 71.59, $F=107.26, \mathrm{p}<0.001)$, and coral skeleton (ANOVA, $\mathrm{MS}=71.59, F=107.26, \mathrm{p}<0.001$ ) were observed in those corals with symbiotic cyanobacteria and always exhibited significantly depleted $\delta^{13} \mathrm{C}$ values compared to corals without cyanobacteria (Fig. 3b).

The number of zooxanthellae per unit surface area was not significantly different (ANOVA, MS =0.18, $F=$ $0.44, \mathrm{p}<0.05)$ between colonies with cyanobacteria $\left(3.26 \pm 0.3 \mathrm{SE} \times 10^{6}\right.$ cells $\left.\mathrm{cm}^{-2}\right)$ and without cyanobacteria $\left(2.92 \pm 0.42 \mathrm{SE} \times 10^{6}\right.$ cells $\left.\mathrm{cm}^{-2}\right)$. Likewise, the mean size (measured as ESD) of zooxanthellae from colonies with cyanobacteria $(14.30 \mu \mathrm{m} \pm 0.42 \mathrm{SE}) \mathrm{did}$ not differ significantly (ANOVA, MS $=0.12, F=1.7, \mathrm{p}<$ $0.05)$ from colonies without cyanobacteria $(14.37 \mu \mathrm{m} \pm$ $0.41 \mathrm{SE})$, but the zooxanthellae from colonies with cyanobacteria had significantly (ANOVA, MS = $25187.42, F=1079.41, \mathrm{p}<<0.001)$ greater DNA content per cell, measured as relative Picogreen fluorescence, than did con-specifics without cyanobacteria (Fig. 4). The colonies used were collected at midday, which did not coincide with peak rates of nitrogen fixation.

The $P-E$ curves for whole colonies of Montastraea cavernosa with and without symbiotic cyanobacteria revealed that there were significant differences in maximum productivity between brown/green and orange colonies $(\mathrm{ANOVA}, \mathrm{MS}=1.808, F=141.14, \mathrm{p}=$
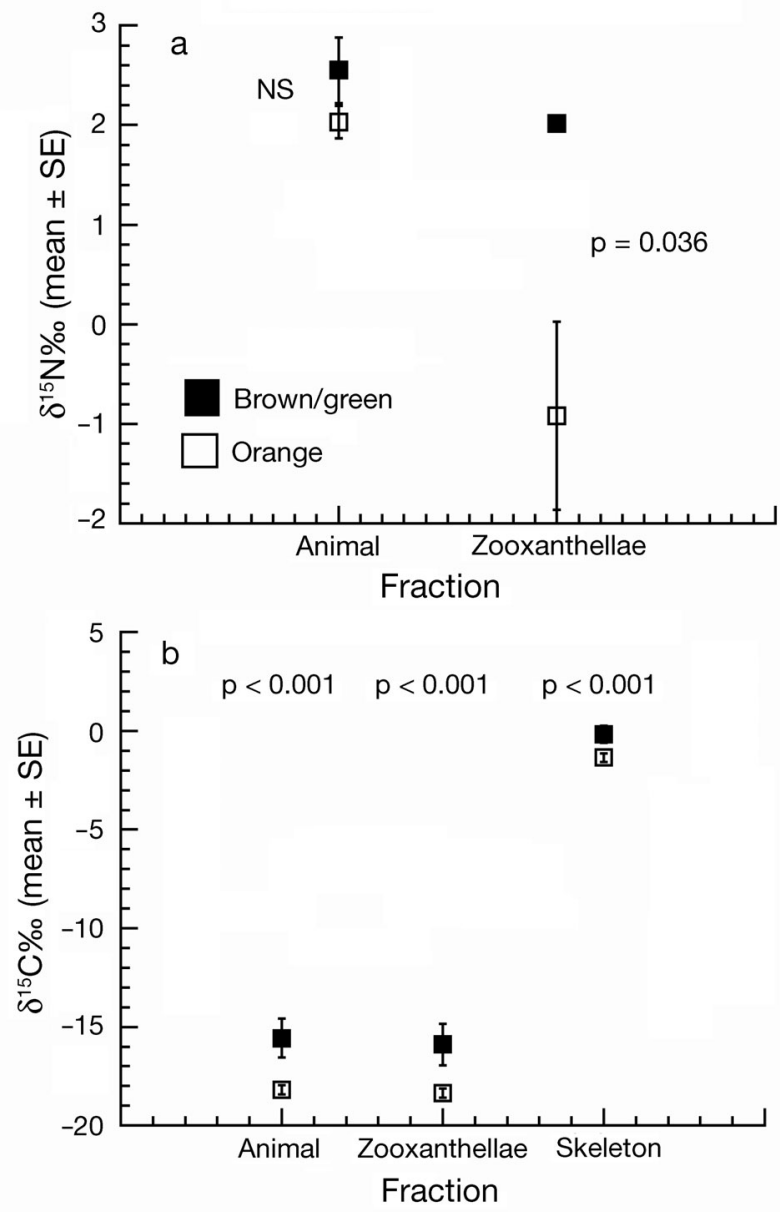

Fig. 3. Montastraea cavernosa. (a) Stable $\delta^{15} \mathrm{~N}$ isotope results for animal and zooxanthellae fractions of brown/green $(n=3)$ and orange $(n=3)$ colonies. (b) Stable $\delta^{13} C$ isotope results for animal, zooxanthellae, and skeletal fractions of brown/green $(n=3)$ and orange $(n=3)$ colonies. Results expressed as mean \pm SE. NS: not significant

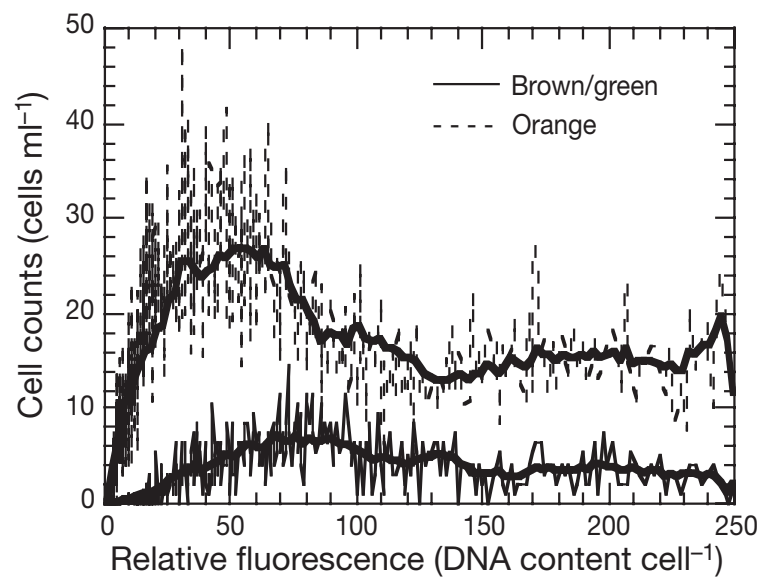

Fig. 4. Montastraea cavernosa. Cellular DNA content measured as relative fluorescence of Picogreen staining on isolated zooxanthellae from brown/green $(\mathrm{n}=3)$ and orange $(\mathrm{n}=3)$ colonies. Thick solid lines through distributions are smoothed curves for easier visualization 


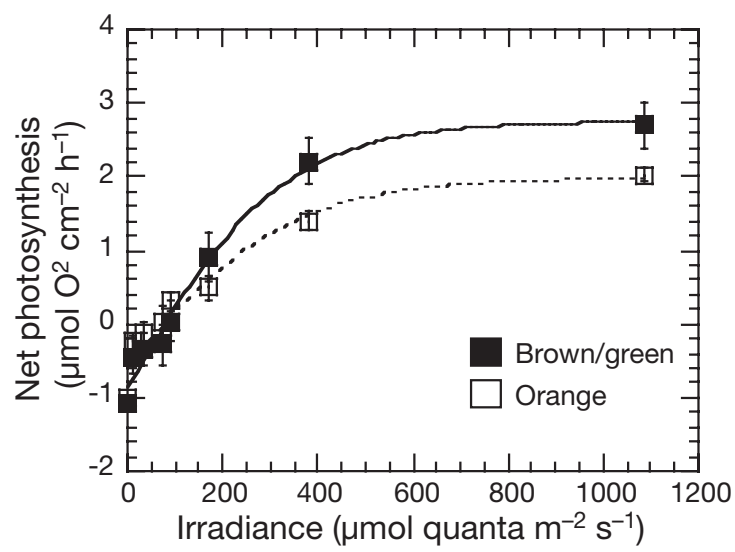

Fig. 5. Montastraea cavernosa. Net photosynthesis-to-irradiance $(P-E$, oxygen flux) curves for brown/green $(\mathrm{n}=3)$ versus orange $(n=3)$ colonies. Points of the curve are mean \pm SE

0.0003; brown/green: $3.63 \pm 0.22 \mathrm{SE} \mu \mathrm{mol} \mathrm{O}_{2} \mathrm{~cm}^{-2} \mathrm{~h}^{-1}$; orange: $2.53 \pm 0.29 \mathrm{SE} \mu \mathrm{mol} \mathrm{O} \mathrm{Cm}^{-2} \mathrm{~h}^{-1}$ ) (Fig. 5). Rates of post-illumination respiration, while greater for orange $\left(-1.728 \pm 0.218 \mathrm{SE} \mu \mathrm{mol} \mathrm{O}_{2} \mathrm{~cm}^{-2} \mathrm{~h}^{-1}\right)$ than for brown/green colonies $\left(-1.627 \pm 0.024 \mathrm{SE} \mu \mathrm{mol} \mathrm{O} \mathrm{Cm}^{-2}\right.$ $\mathrm{h}^{-1}$ ), did not differ significantly from each other (ANOVA, MS $=0.015, F=1.53, \mathrm{p}>0.05$ ). Differences observed in the light-limited portion of the fitted curves were also not significantly different (ANOVA, $\mathrm{MS}=6 \times 10^{-6}, F=1.50, \mathrm{p}>0.05$ ). Maximum quantum yields of PSII fluorescence for the zooxanthellae of colonies with endosymbiotic cyanobacteria $(n=3$, $0.654 \pm 0.0006 \mathrm{SE}$ ) did not differ signficantly (ANOVA, MS $=0.001, F=0.076, p>0.05$ ) from colonies without endosymbiotic cyanobacteria $(n=3,0.637 \pm 0.013 \mathrm{SE})$, and colonies with cyanobacteria exhibited a $22 \%$ increase in phycoerythrin emission in the range of 585 to $590 \mathrm{~nm}$ when exposed to the herbicide DCMU.

Measurements of the optical properties of reef waters in the Bahamas have an average downwelling attenuation coefficient $\left(k_{\mathrm{d}} \mathrm{m}^{-1}\right)$ for PAR of $0.160 \mathrm{~m}^{-1}$ (M. P. Lesser unpubl. data). Using this attenuation coefficient and the oxygen fluxes across the full range of irradiances from the $P$ - $E$ curves (Fig. 5), we modeled the diurnal variations in photosynthesis along a depth profile for a cloudless day of $12 \mathrm{~h}$ of daylight. Then, using the modeled rates of photosynthesis, we calculated the total amount of time available to fix nitrogen knowing the irradiances at which the flux of oxygen can support cyanobacterial respiration that in turn supply reducing power and ATP, but that are low enough to prevent nitrogenase inhibition (e.g. Fig. 2). In this context, as a first approximation to satisfy these conditions, we assumed that nitrogen fixation occurs exclusively during the illuminated periods of the day under irradiances below the compensation point $+10 \%$ of
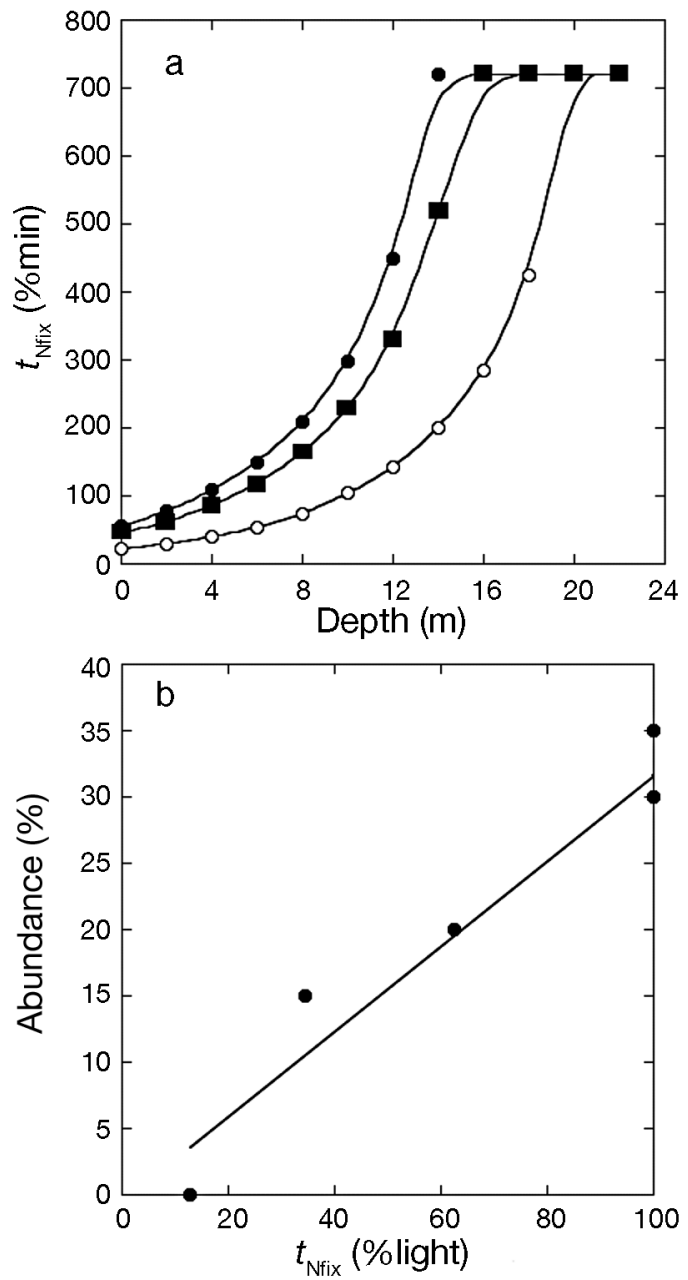

Fig. 6. Montastraea cavernosa. (a) Relationship between the time in which nitrogen fixation can take place $\left(t_{\mathrm{Nfix}}\right)$ in colonies with endosymbiotic cyanobacteria and depth; O: predictions based on the assumption that nitrogen fixation occurred only at irradiances below the compensation point; $\mathbf{\square}$ : results of the model simulation using empirically obtained respiration rates; $\bullet$ : results of the model simulation assuming that nitrogen fixation occurred only at irradiances below the compensation point $+10 \%$ ambient irradiance. (b) Using percent abundance data of colonies with endosymbiotic cyanobacteria (Fig. 1) and simulation data of the percentage of daylight irradiances below the compensation point $+10 \%$ ambient irradiance, we obtain a significant functional relationship (ANOVA, $\mathrm{p}<0.05 ; y=0.32139 x-0.54562 ; \mathrm{R}^{2}=0.903$ ) that predicts increasing abundances of these corals with increasing depth

ambient irradiance, in order to avoid severe hyperoxia and inhibition of nitrogenase. Then, from the modeled diurnal variations in photosynthesis, we calculated the amount of time in which nitrogen fixation can take place $\left(t_{\text {Nfix }}\right)$ at different depths based on these conditions (Fig. 6a). The variable $t_{\text {Nfix }}$ increases exponentially as a function of depth, until peaking at depths greater than $12 \mathrm{~m}$ where the irradiances at those 
depths maximize conditions conducive to nitrogen fixation. The rate of increase of $t_{\text {Nfix }}$ and the depth at which nitrogen fixation prevails during all daylight hours are dependent on the optical properties of the water column and the respiratory demands of the coral (Fig. 6a). Additionally, when it is assumed that nitrogen fixation occurs at irradiances below the compensation point $+10 \%, t_{\text {Nfix }}$ is significantly correlated (ANOVA, $\mathrm{p}<0.05 ; \mathrm{R}^{2}=0.903$ ) with the relative abundances of $M$. cavernosa with endosymbiotic nitrogenfixing cyanobacteria (see Figs. $1 \& 6 b$ ).

\section{DISCUSSION}

These results show that the endosymbiotic cyanobacteria expressing nitrogenase (Lesser et al. 2004) in association with Montastraea cavernosa are capable of fixing nitrogen. The in hospite environment of zooxanthellate corals might at first seem to be an unlikely place for nitrogen fixation owing to the hyperoxic environment of coral tissues during the daytime (Shashar et al. 1993, Kühl et al. 1995) and the sensitivity of nitrogenase to molecular and reduced forms of oxygen such as superoxide radicals (Fay 1992, Berman-Frank et al. 2003). However, corals also experience profound hypoxia and sometimes anoxia (Shashar et al. 1993, Kühl et al. 1995) during nighttime, which can be a signal for the up-regulation of the genes encoding nitrogenase (Fay 1992, Berman-Frank et al. 2003). Without heterocysts to protect nitrogenase from molecular oxygen or ROS, cyanobacteria often employ a strategy of temporal separation of photosynthesis and nitrogen fixation to avoid the loss of nitrogenase activity (Fay 1992). The sensitivity to oxygen and ROS varies among cyanobacteria, with many species able to fix nitrogen under anaerobic, microaerobic, and fully aerobic conditions (Fay 1992, Bergman et al. 1997). Exposure to oxygen inactivates the nitrogenase protein without affecting either transcription or translation of the gene, while exposure to ROS could denature the protein (Berman-Frank et al. 2005). Although temporal separation of nitrogen fixation is evident in $M$. cavernosa (Fig. 2), we do not know what other strategies are employed to protect nitrogenase within the cellular environment of the coral host.

Many nitrogen-fixing cyanbacteria exhibit a diurnal pattern of nitrogen fixation that avoids exposure to molecular oxygen or ROS by not only producing nitrogenase in the dark but also fixing nitrogen in the dark (Bergman et al. 1997, Berman-Frank et al. 2003). Additionally, other species grown under constant illumination exhibit a circadian rhythm in nitrogen fixation (Bergman et al. 1997), while some species (e.g. Trichodesmium sp.) can fix nitrogen during the day
(Berman-Frank et al. 2003). The pattern of diurnal nitrogen fixation observed in Montastraea cavernosa suggests that nitrogen fixation occurs during a window of time in which sub-saturating irradiances are not sufficient to result in net positive photosynthesis in the zooxanthellae. The amount of oxygen produced is sufficient to serve as a terminal electron acceptor for respiration in the symbiotic population of cyanobacteria, but not high enough to inactivate the enzyme nitrogenase. Some nitrogen fixation does occur in the dark, and we hypothesize that the cyanobacteria could potentially ferment glycerol in the absence of oxygen (Schneegurt et al. 1997) and supply enough energy for the lower rates observed during that period of time. The pattern of nitrogen fixation is consistent with our observations and modeling that the proportion of $M$. cavernosa colonies with symbiotic cyanobacteria increases with depth, because the time available for nitrogen fixation increases with depth as irradiance decreases (Fig. 6a).

Previous studies using fluorescence lifetime analyses clearly showed the uncoupling of primary photochemistry from the light harvesting pigments, and the subsequent reduction in photosynthetic electron transport in these endosymbiotic cyanobacteria (Lesser et al. 2004). Additionally, when we exposed corals containing symbiotic cyanobacteria to DCMU and measured changes in phycoerythrin fluorescence, we observed an increase of only $22 \%$ relative to control corals, which indicates that the majority of the reaction centers are already uncoupled from photosynthetic electron transport in the cyanobacteria. Both sources of data show that most of these cyanobacteria are not photosynthesizing at all, or photosynthesizing very little in hospite. We hypothesize that these cyanobacteria are operating heterotrophically and respiring glycerol to provide the energy and reductant required for nitrogen fixation. Glycerol is the major carbon compound translocated from the symbiotic zooxanthellae to the host tissues (Muscatine 1990), and cyanobacterial symbionts would therefore be exposed to high concentrations of glycerol in hospite. A direct test of this hypothesis remains to be undertaken, but the significantly depleted stable $\delta^{13} \mathrm{C}$ values in the animal, zooxanthellae, and skeleton of Montastraea cavernosa colonies with cyanobacterial symbionts provides important supportive evidence. Owing to metabolic fractionation, depleted $\delta^{13} \mathrm{C}$ values normally suggest a decrease in photosynthesis or light levels, but are also an indication of an increase in heterotrophy (Grottoli \& Wellington 1999). Our observations of the increase in respiration and decrease in net productivity of corals with cyanobacteria, together with depleted $\delta^{13} \mathrm{C}$ values compared with con-specifics at the same depth and downwelling irradiances, support our view that the cyanobacteria are operating heterotrophically. 
Operating heterotrophically may actually be advantageous because cyanobacterial respiration could lower oxygen concentrations, and the inhibition of nitrogenase, around the sites of nitrogen fixation. In an analogous situation, several species of free-living cyanobacteria are relegated to narrow environmental niches of low oxygen concentration in which their nitrogenase enzyme can operate under microaerobic conditions that prevents the inactivation of nitrogenase, but provides enough oxygen for respiratory processes to provide the energy and reductant for nitrogen fixation (Fay 1992, Berman-Frank et al. 2003). Recent experiments on the cyanobacterium Trichodesmium sp. revealed the important role of a lowoxygen environment and respiration on the regulation of nitrogen fixation through the competition for reducing equivalents between nitrogen fixation and respiratory pathways (Staal et al. 2007).

What is the fate of the fixed nitrogen products in this system? Our stable isotope results showed that the zooxanthellae are using the products of nitrogen fixation. Recent analyses of $\delta^{15} \mathrm{~N}$ in corals over a wide range of temporal and spatial scales revealed no similar isotopic signals (Heikoop et al. 2000, Swart et al. 2005), except in samples of Montastraea cavernosa from Jamaica (Muscatine \& Kaplan 1994). The ambient atmosphere has a $\delta^{15} \mathrm{~N}$ value of $0.00 \%$ while seawater is $\sim 1.0 \%$ (Owens 1987, Kayanne et al. 2005). The significantly depleted $\delta^{15} \mathrm{~N}$ values $(<0.00 \%$ ) in the zooxanthellae fraction of colonies with symbiotic cyanobacteria indicate the use of DIN derived from nitrogen fixation within the tissues of the coral, in contrast with the zooxanthellae fraction of con-specifics at the same depth without cyanobacterial symbionts that exhibited $\delta^{15} \mathrm{~N}$ values significantly greater than the value of $\sim 1.0 \%$ for seawater.

The first product available as a result of nitrogen fixation is ammonium $\left(\mathrm{NH}_{4}{ }^{+}\right)$. While we do not know how much of this fixed source of DIN might be utilized by the symbiotic cyanobacteria themselves, it is apparent that either $\mathrm{NH}_{4}{ }^{+}$from nitrogen fixation is being utilized by the zooxanthellae preferentially, or that another product with a strong nitrogen fixation signal, such as glutamate or glutamine, is being utilized by the zooxanthellae. Zooxanthellae are known to express a glutamate synthase-glutamine synthetase (GS/GOGAT) system, which is their primary $\mathrm{NH}_{4}{ }^{+}$assimilatory pathway (Anderson \& Burris 1987). Previous studies on symbiotic cnidarians also showed that $\mathrm{NH}_{4}{ }^{+}$is assimilated preferentially, but not solely, into glutamate and glutamine by the zooxanthellae (Swanson \& HoeghGuldberg 1998). Some studies also showed that the assimilation of $\mathrm{NH}_{4}{ }^{+}$by the zooxanthellae is significantly greater than that by the animal tissue (Roberts et al. 1999, Grover et al. 2002), and this might provide an explanation for the absence of a significantly depleted $\delta^{15} \mathrm{~N}$ signature in the animal compartment of the orange Montastraea cavernosa colonies.

Another indication of nutrient supplementation by fixed nitrogen products is the distribution of cellular DNA content in the zooxanthellae from colonies with and without endosymbiotic cyanobacteria, from which we can infer rates of cell division (Smith \& Muscatine 1999). The pattern we observed indicates that many of the zooxanthellae in colonies with and without cyanobacteria are in the $G_{1}$ phase of the cell cycle as previously described (Smith \& Muscatine 1999), but that more zooxanthellae are in the DNA synthesis (S) and gap $\left(\mathrm{G}_{2}\right)+$ mitosis $(\mathrm{M})$ phases of the cell cycle in those colonies with endosymbiotic cyanobacteria, as indicated by their greater DNA content per cell. This suggests that zoo-xanthellae can use these supplementary sources of nitrogen and increase their growth rates without compromising the integrity of the symbiosis, as was also shown for zooxanthellate anemones provided exogenous sources of food or inorganic nutrients (Smith \& Muscatine 1999). Whether the symbiosis compensates by increasing the daily rates of zooxanthellae expulsion is unknown. Additionally, these differences are unlikely to be attributed to physiological differences in zoo-xanthellae, because conspecifics with and without cyanobacteria have the same dominant genotype (C3 ITS signature, M. P. Lesser unpubl. data).

The presence of cyanobacterial symbionts in zooxanthellate corals that can fix nitrogen represents not just a novel microbial consortium of photosynthetic eukaryotes and prokaryotes, but one that raises interesting questions about nitrogen limitation in corals (Falkowski et al. 1993). Why are all individuals of Montastraea cavernosa not apparently in symbiosis with this cyanobacterium? One possible explanation is that host differences in the ability to enter into these associations are important, or that potentially different strains of this cyanobacterium exist with different capabilities to enter into a symbiotic association. These and related questions are the subject of ongoing work. We do know, however, that prokaryotes fixing nitrogen are much more abundant in the oceans than previously believed, and that many of these are unicellular cyanobacteria related to the genera Gloeothece, Synechococcus, Crocosphaera and Synechocystis (Zehr et al. 2001, 2007). These unicellular groups are in the Order Chroococcales, as are the cyanobacterial endosymbionts of $M$. cavernosa (Lesser et al. 2004). This group of free-living unicellular cyanobacteria (Groups A and B; Zehr et al. 2001, 2007) also exhibits a pattern of nitrogen fixation similar to that reported here, with maximum nitrogen fixation potential (number of nif $\mathrm{H}$ transcripts) occurring in the early morning and early 
afternoon (Church et al. 2005). As we continue to examine the taxonomy of nitrogen fixers in the oceans, many more representatives of the unicellular Chroococcales appear to have the capability to fix nitrogen.

If the occurrence of this consortium in other species of scleractinian corals residing in oligotrophic tropical waters is more common than previously believed, it could potentially provide an important supplementary source of a limiting element for zooxanthellate corals. Additionally, corals release large quantities of dissolved organic material containing high concentrations of both organic and inorganic sources of nitrogen (Wild et al. 2005), which has implications for the biogeochemical fluxes of nitrogen in carbonate sands and pore waters, and therefore nitrogen budgets on coral reefs. At the organismal level, the addition of new nitrogen from endosymbiotic cyanobacteria in corals raises questions about our current understanding of the role of nitrogen as a limiting and regulatory element in these associations.

Acknowledgements. We thank Ron Johnstone, Javier Ania, Andrea Grottoli, and Ania Banaszak for technical assistance with the nitrogen fixation and stable isotope analyses, and the J. J. MacIsaac Facility for Aquatic Cytometry, Bigelow Laboratory for Ocean Sciences for the flow cytometry data. This research was partially funded by the Coral Reef Targeted Research (CRTR) Program. The CRTR Program is a partnership between the Global Environmental Facility, the World Bank, The University of Queensland (Australia), the NOAA, and approximately 40 research institutes and other third parties around the world. The experiments conducted for this study comply with the current laws of the Bahamas, Mexico, and the USA.

\section{LITERATURE CITED}

Anderson SL, Burris JE (1987) Role of glutamine synthetase in ammonia assimilation by symbiotic marine dinoflagellates (zooxanthellae). Mar Biol 94:451-458

Arrigo KR (2005) Marine microorganisms and global nutrient cycles. Nature 437:349-355

Bergman B, Gallon JR, Rai AN, Stal LJ (1997) N $\mathrm{N}_{2}$ fixation by non-heterocystous cyanobacteria. FEMS Microbiol Rev 19:139-185

Berman-Frank I, Lundgren P, Falkowski P (2003) Nitrogen fixation and photosynthetic oxygen evolution in cyanobacteria. Res Microbiol 154:157-164

Berman-Frank I, Chen YB, Gerchman Y, Dismukes GC, Falkowski PG (2005) Inhibition of nitrogenase by oxygen in marine cyanobacteria controls the global nitrogen and oxygen cycles. Biogeosci Disc 2:261-273

Church MJ, Short CM, Jenkins BD, Karl DM, Zehr JP (2005) Temporal patterns of nitrogenase gene (nifH) expression in the oligotrophic North Pacific Ocean. Appl Environ Microbiol 71:5362-5370

D'Elia CF, Wiebe WJ (1990) Biogeochemical cycles in coralreef ecosystems. In: Dubinsky Z (ed) Coral reefs: ecosystems of the world, Vol 25. Elsevier, Amsterdam, p 49-74
Falcón LI, Carpenter EJ, Bergman B, Capone D (2004) N N$_{2}$-fixation by unicellular bacterioplankton in the Atlantic and Pacific Oceans: phylogeny and in situ rates. Appl Environ Microbiol 70:765-770

Falkowski PG, Dubinsky Z, Muscatine L, McCloskey LR (1993) Population control in symbiotic corals. BioScience 43:453-464

Fay P (1992) Oxygen relations of nitrogen fixation in cyanobacteria. Microbiol Rev 56:340-373

Grottoli AG, Wellington GM (1999) Effect of light and zooplankton on skeletal $\delta^{13} \mathrm{C}$ values in the eastern Pacific corals Pavona clavus and Pavona gigantean. Coral Reefs 18:29-41

Grover R, Maguer JF, Reynaud-Vaganay R, Ferrier-Pages C (2002) Uptake of ammonium by the scleractinian coral Stylophora pistillata: effect of feeding, light, and ammonium concentrations. Limnol Oceanogr 47:782-790

Heikoop JM, Dunn JJ, Risk MJ, Tomascik T, Schwarcz HP, Sandeman IM, Sammarco PW (2000) $\delta^{15} \mathrm{~N}$ and $\delta^{13} \mathrm{C}$ of coral tissue show significant inter-reef variation. Coral Reefs 19:189-193

Jassby AD, Platt T (1976) Mathematical formulation of the relationship between photosynthesis and light for phytoplankton. Limnol Oceanogr 21:540-547

Kayanne H, Hirota M, Yamamuro M, Koike I (2005) Nitrogen fixation of filamentous cyanobacteria in a coral reef measured using three different methods. Coral Reefs 24: $197-200$

Kühl M, Cohen Y, Dalsgaard T, Jørgensen BB, Revsbech NP (1995) Microenvironment and photosynthesis of zooxanthellae in scleratinian corals studied with microsensors for $\mathrm{O}_{2}, \mathrm{pH}$, and light. Mar Ecol Prog Ser 117:159-172

Lesser MP (2004) Experimental biology of coral reef ecosystems. J Exp Mar Biol Ecol 300:217-252

Lesser MP, Mazel CH, Gorbunov MY, Falkowski PG (2004) Discovery of symbiotic nitrogen-fixing cyanobacteria in corals. Science 305:997-1000

Litvaitis MK (2002) A molecular test of cyanobacterial phylogeny: inferences from constraint analyses. Hydrobiologia 468:135-145

Marsh JA (1970) Primary productivity of reef-building calcareous algae. Ecology 51:255-263

Muscatine L (1990) The role of symbiotic algae in carbon and energy flux in reef corals. In: Dubinsky Z (ed) Coral reefs: ecosystems of the world, Vol 25. Elsevier, Amsterdam, p 75-87

Muscatine L, Kaplan IR (1994) Resource partitioning by reef corals as determined from stable isotope composition II. $\delta^{15} \mathrm{~N}$ of zooxanthellae and animal tissue versus depth. Pac Sci 48:304-312

Owens NJP (1987) Natural variations in ${ }^{15} \mathrm{~N}$ in the marine environment. Adv Mar Biol 24:389-451

Roberts JM, Davies PS, Fixter LM, Preston T (1999) Primary site and initial products of ammonium assimilation in the symbiotic sea anemone Anemonia viridis. Mar Biol 135: $223-236$

Rodrigues LJ, Grottoli AG (2006) Calcification rate and the stable carbon oxygen, and nitrogen isotopes in the skeleton, host tissue, and zooxanthellae of bleached and recovering Hawaiian corals. Geochim Cosmochim Acta 70:2781-2789

Rowher F, Seguritan V, Azam F, Knowlton N (2002) Diversity and distribution of coral-associated bacteria. Mar Ecol Prog Ser 243:1-10

Schneegurt MA, Sherman DM, Sherman LA (1997) Growth, physiology, and ultrastructure of a diazotrophic cyanobacterium, Cyanothece sp. strain ATCC 51142, in mixotrophic 
and chemoheterotrophic cultures. J Phycol 33:632-642

Shashar N, Cohen Y, Loya Y (1993) Extreme diel fluctuations of oxygen in diffusive boundary layers surrounding stony corals. Biol Bull (Woods Hole) 185:455-461

Shashar N, Cohen Y, Loya Y, Star N (1994) Nitrogen fixation (acetylene reduction) in stony corals: evidence for coral-bacterial interactions. Mar Ecol Prog Ser 111: $259-264$

Smith GJ, Muscatine L (1999) Cell cycle of symbiotic dinoflagellates: variation in $\mathrm{G}_{1}$ phase-duration with anemone nutritional status and macronutrient supply in the Aiptasia pulchella-Symbiodinium pulchrorum symbiosis. Mar Biol 134:405-418

Staal M, Rabouille S, Stal LJ (2007) On the role of oxygen for nitrogen fixation in the marine cyanobacterium Trichodesmium sp. Environ Microbiol 9:727-736

Steunou A, Bhaya D, Bateson MM, Melendrez MC and 5 others (2006) In situ analysis of nitrogen fixation and metabolic switching in unicellular thermophilic cyanobacteria inhabiting hot spring microbial mats. Proc Natl Acad Sci USA 103:2398-2403

Swanson R, Hoegh-Guldberg O (1998) Amino acid synthesis in the symbiotic sea anemone Aiptasia pulchella. Mar Biol 131:83-93

Editorial responsibility: Charles Birkeland (Contributing Editor), Honolulu, Hawaii, USA
Swart PK, Saied A, Lamb K (2005) Temporal and spatial variation in the $\delta^{15} \mathrm{~N}$ and $\delta^{13} \mathrm{C}$ of coral tissue and zooxanthellae in Montastraea faveolata collected from the Florida reef tract. Limnol Oceanogr 50:1049-1058

Veldhuis MJ, Cucci TL, Sieracki ME (1997) Cellular DNA content of marine phytoplankton using two new fluorochromes: taxonomic and ecological implications. J Phycol 33:527-541

Wiebe WJ, Johannes RE, Webb KL (1975) Nitrogen fixation in a reef community. Science 188:257-259

Wild C, Woyt H, Huettel M (2005) Influence of coral mucus on nutrients on nutrient fluxes in carbonate sands. Mar Ecol Prog Ser 287:87-98

Williams WM, Viner AB, Broughton WJ (1987) Nitrogen fixation (acetylene reduction) associated with the living coral Acropora variabilis. Mar Biol 94:531-535

Zehr JP, Waterbury JB, Turner PJ, Montoya JP, Omoregia E, Steward GF, Hansen A, Karl DM (2001) Unicellular cyanobacteria fix N2 in the subtropical North Pacific Ocean. Nature 412:635-638

Zehr JP, Montoya JP, Jenkins BD, Hewson I and 5 others (2007) Experiments linking nitrogenase gene expression to nitrogen fixation in the North Pacific subtropical gyre. Limnol Oceanogr 52:169-183

Submitted: December 9, 2006; Accepted: April 3, 2007 Proofs received from author(s): September 11, 2007 